This document is the accepted manuscript version of the following article:

Fawcett, D., Verhoef, W., Schläpfer, D., Schneider, F. D., Schaepman, M. E., \& Damm, A. (2018). Advancing retrievals of surface reflectance and vegetation indices over forest ecosystems by combining imaging spectroscopy, digital object mode1s, and 3D canopy model1ing. Remote Sensing of Environment, 204, 583-595.

https://doi.org/10.1016/j.rse.2017.09.040

This manuscript version is made available under the CC-BY-NC-ND 4.0 1icense http:// creativecommons.org/1icenses/by-nc-nd/4.0/

\title{
Advancing retrievals of surface reflectance and vegetation indices over forest ecosystems by combining imaging spectroscopy, digital object models, and 3D canopy modelling
}

\author{
D. Fawcett ${ }^{\mathrm{a}, *}$, W. Verhoef ${ }^{\mathrm{b}}$, D. Schläpfer ${ }^{\mathrm{c}}$, F.D. Schneider ${ }^{\mathrm{a}}$, M.E. Schaepman ${ }^{\mathrm{a}}$, \\ A. Damm ${ }^{\mathrm{a}}$ \\ ${ }^{a}$ Remote Sensing Laboratories, University of Zurich, Winterthurerstrasse 190, 8057 Zurich, \\ Switzerland \\ ${ }^{b}$ University of Twente, Faculty of Geo-Information Science and Earth Observation (ITC), \\ P.O. Box 217, 7500 AE Enschede, The Netherlands \\ ${ }^{c}$ ReSe Applications Schläpfer, Langeggweg 3, 9500 Wil, Switzerland
}

\begin{abstract}
Imaging spectroscopy based methods offer unique capabilities for retrieving narrow-band vegetation indices which can be empirically related to functional traits of plants. However, in areas with complex topography, illumination effects affect the retrieval of such indices from high spatial resolution airborne or satellite data. Irradiance components at the pixel level are determined by atmospheric composition, as well as instantaneous illumination-surface-sensor geometries. An accurate pixel-wise description of direct and diffuse irradiance components is necessary to perform atmospheric corrections, finally resulting in improved surface reflectances and hence products. We assess three atmospheric correction strategies, differing in their approaches to simulate instantaneous as well as pixel-wise abundances of diffuse and direct irradiance. We use physicallybased approaches in combination with either digital elevation models (DEM), fine resolution digital object models (DOM), or 3D modelling output from the Discrete Anisotropic Radiative Transfer (DART) model. The such obtained topof-canopy reflectances at the Laegern test-site in Switzerland, are used to assess
\end{abstract}

\footnotetext{
${ }^{*}$ Corresponding author

Email address: dominic.fawcett@geo.uzh.ch (D. Fawcett)
} 
retrieval improvement for a set of indices (Normalized Difference Vegetation Index (NDVI), Photochemical Reflectance Index (PRI), as well as chlorophyll and carotenoid indices). We demonstrate that both, the DOM and the DART based approach, improve the retrievals for flat cast-shadows by $\leq 71 \%$ compared to using a DEM. In dense forest areas, improvements are less significant. Remaining key issues are related to overestimating surface reflectance under extreme illumination conditions.

Keywords: Imaging spectroscopy, remote sensing, atmospheric correction, shadow, APEX, diffuse and direct irradiance, DOM, DART, NDVI, PRI, chlorophyll, carotenoids

\section{Introduction}

Imaging spectroscopy is often employed to infer physiological, biochemical, 3 and structural vegetation traits that eventually allow assessing and monitoring 4 spatio-temporal variations in vegetation functioning, health and status. A wide 5 range of different analytical methods (e.g. vegetation indices, model inversion 6 techniques) are available to retrieve such quantitative information from mea7 sured radiometric signals (Kokaly et al., 2009; Schaepman et al., 2009; Ustin 8 et al., 2009). Increasing spectral resolution of optical sensors offers new op9 portunities in vegetation monitoring, which were not possible before. Besides biochemical vegetation information (e.g. leaf chlorophyll content and leaf water content), functional information such as the de-epoxidation state of xanthop12 hylls (Gamon et al., 1990) and sun-induced chlorophyll fluorescence (Damm 13 et al., 2015a; Rascher et al., 2015) can be retrieved nowadays. The retrieval of such vegetation information is achieved by either measuring subtle changes of leaf reflectance using reflectance based approaches or exploiting narrow atmospheric absorption features using radiance based approaches. Advancements in sensor technology allow combining high spectral with high spatial resolution (Wulder et al., 2004). This information is complex in its nature, in particular due to the increasing shadow fraction for each pixel, in particular in highly ver- 
tically structured vegetation. In particular measurements of individual species, such as trees, are always composed of a mixture of sunlit and shaded parts, complicating retrievals of surface reflectance values as well as functional traits (Gastellu-Etchegorry et al., 1999). Further, highly accurate estimates of surface irradiance are of increasing interest for specialised applications (e.g. Damm et al., 2014). Irradiance varies in intensity and spectral composition, depending on atmospheric composition (Seidel et al., 2012). Direct irradiance at surface level represents radiation which remains un-scattered while diffuse irradiance contains radiation which was previously scattered by gases or aerosols in the atmosphere and by the surroundings of the target surface. Multiple scattering within the atmosphere leads to a wavelength dependent increase of the atmospheric pathway and thus an increase of atmospheric molecular absorption compared to the direct path. It has been demonstrated that these wavelength dependent differences between direct and diffuse irradiance lead to considerable errors in retrieved surface reflectance and subsequently derived vegetation information if pixel-wise estimates of direct and diffuse irradiance are uncertain (Damm et al., 2015b). Accurate and instantaneous atmospheric corrections of high spectral and spatial resolution data are challenging (Matthew et al., 2002; Seidel et al., 2010). The state of the atmosphere at acquisition time plays a vital role because local and temporal variations in water vapour and aerosol loadings impact spectral irradiance estimates (Cho et al., 2003). To overcome this limitation, a precise parameterization of the atmosphere for radiative transfer codes is required (Key \& Schweiger, 1998). In order to properly describe these complex irradiance fields one can no longer assume uniformly flat Earth surfaces or use coarse digital elevation models (DEM) which do not resolve small scale height differences for correction (Richter, 1990, 1998). Several approaches have been discussed to minimize those uncertainties. Minimizing varying illumination effects can be achieved by only considering sunlit pixels (Asner et al., 2015; Malenovský et al., 2013). Other methods include the use of matched filtering of reflectance data to detect and correct shadows (Adler-Golden et al., 2002). More sophisticated approaches make intensive use of auxiliary data. Digital ob- 
ject models (DOM) derived from LiDAR data are used to better represent the surface (Friman et al., 2011). Other approaches involving ray tracing through LiDAR based voxel grids have been proposed (Schläpfer et al., 2003; Kükenbrink et al., 2016). In this study we hypothesize that (1) more accurate irradiance fields can be modelled by using auxiliary, scene specific data and that (2) these irradiance fields can be integrated in the atmospheric correction process to minimize product sensitivity to illumination effects. This will finally lead to (3) retrievals of vegetation indices showing a substantially reduced sensitivity to surface illumination. We evaluate three approaches for atmospheric correction that are all using four-stream theory (Verhoef \& Bach, 2003) and account for direct and diffuse irradiance variations by employing different auxiliary data. All approaches are applied to data acquired with the Airborne Prism Experiment (APEX) imaging spectrometer (Schaepman et al., 2015), allowing an evaluation based on commonly encountered illumination situations. We derive vegetation indices (Normalized Difference Vegetation Index (NDVI), Photochemical Reflectance Index (PRI) and two pigment indices for chlorophyll (CHL) and carotenoids $(\mathrm{CAR})$ ) to demonstrate the impact of the correction methods on remote sensing products.

\section{Study site and data}

\subsection{Study site}

The Laegern study site is a limestone hill northwest of Zurich, Switzerland $\left(47^{\circ} 28^{\prime} 54.75^{\prime} \mathrm{N} 8^{\circ} 23^{\prime} 37.82^{\prime \prime E}, 866 \mathrm{~m}\right.$ a.s.l.), stretching West to East. The site is mainly covered by a temperate mixed forest with a high diversity of tree species (dominated by beech, ash, sycamore and spruce) of different ages and sizes (Eugster et al., 2007). The Laegern is a well-studied site and contains a flux tower which is part of the AERONET (Holben et al., 1998) and FLUXNET (Baldocchi et al., 2001) measurement networks. The extent of the study site used here contains the Laegern forest as well as surrounding agricultural areas. 


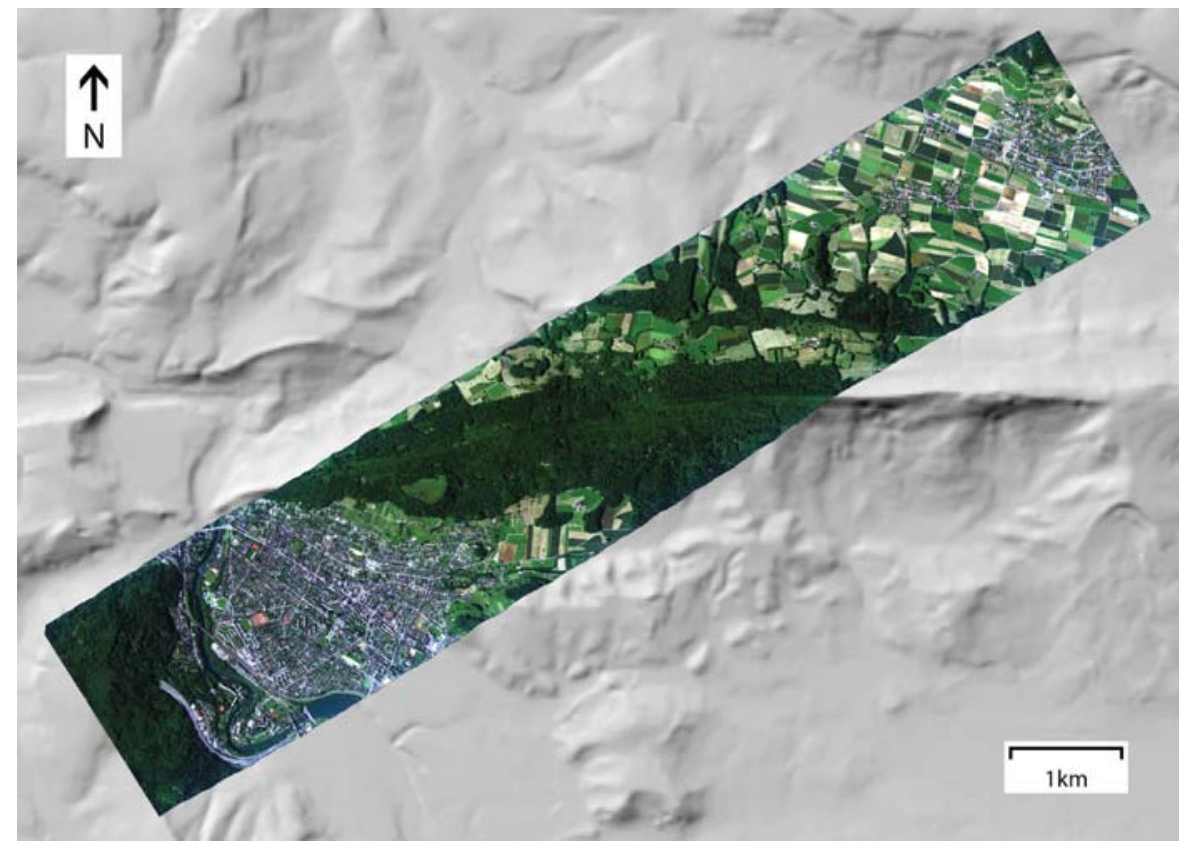

Figure 1: APEX flight line (at-sensor radiance, RGB colour composite) of the Laegern study site (June 26, 2010, 15:30 UTC). The background is a hillshaded DEM illustrating scene topography (DHM25 from Swisstopo, Switzerland).

\subsection{Imaging spectrometer data}

The main datasets used are two flight lines covering the study site (fig. 1). They were acquired by APEX on the 26th of June 2010 at 15:30 UTC and on acquisition time are listed in tab. (1). APEX is an airborne pushbroom imaging spectrometer covering the $372 \mathrm{~nm}$ to $2500 \mathrm{~nm}$ region in 312 contiguous spectral bands. In this study, a spectral subset of the available bands is used, ranging from $399 \mathrm{~nm}$ to $914 \mathrm{~nm}$, as these bands contain the necessary information to derive the desired vegetation indices and processing time is reduced. In this wavelength range, APEX shows a spectral sampling interval of 0.45-7.5 $\mathrm{nm}$ and a spectral resolution of 0.86-15 $\mathrm{nm}$ (Schaepman et al., 2015). The data was pre-processed and provided as radiometrically, spectrally and geometrically calibrated radiances (level 1) (Hueni et al., 2009). The two datasets were then 
georectified using the PARGE software (Schläpfer \& Richter, 2002). The resulting pixel size was $2.0 \mathrm{~m}$ and based on 18 ground control points, a root mean square error (RMSE) of $2.05 m \pm 1.1 \mathrm{~m}$ was calculated. Most of the analysis is constrained to a spatial subset covering around $3.5 \mathrm{~km}^{2}$ with a maximum width of $3.6 \mathrm{~km}$ and maximum length of $2.4 \mathrm{~km}$ due to the smaller spatial extent of the auxiliary data used. The dataset acquired on the 26th acts as primary dataset since it shows more extreme illumination conditions at acquisition time. The dataset of the 29th is used for cross-validation purposes.

Table 1: Solar zenith and azimuth angles at acquisition time for the two acquisitions.

\begin{tabular}{llll}
\hline Day & Time & Solar zenith & Solar azimuth \\
\hline June 26 & 15:30 UTC & 48.1 & 259.0 \\
June 29 & 10:00 UTC & 29.3 & 138.5 \\
\hline
\end{tabular}

\subsection{Elevation models and derived datasets}

Two data sources were used to calculate elevation data for further analysis, 1) the swissALTI3D data product (Swisstopo, Switzerland), resolving terrain elevation in $2 m$ spatial resolution, and 2) an airborne laser scanning (ALS) based surface height measurements with a $1 \mathrm{~m}$ foot print size (cf. Schneider et al., 2014). The ALS dataset was integrated in the swissALTI3D elevation model to increase precision of available height and crown topography information. The spatial resolution of this combined data set was resampled to $2 m$ to fit the APEX resolution. Two elevation models are derived from this elevation data set and act for further analysis, a DOM and a DEM. The DOM features the surface height information of $2 \mathrm{~m}$ spatial resolution. For the DEM, elevation information was smoothed using a large window low-pass filter. This preserves overall canopy height over forested areas but single trees are not resolved due to the smoothing. From both elevation models, datasets of slope, aspect and illumination were derived using the PARGE software, neglecting reflected terrain irradiance from adjacent pixels. The illumination value is represented by the cosine of the local illumination angle $\left(\cos \theta_{i l}\right)$. For the DOM, a binary cast-shadow mask 
was calculated using PARGE. The cast shadow calculation is based on a ray tracing algorithm which requires the solar azimuth and elevation angles as well as the DOM as input. Obscured pixels are flagged as cast shadows. These are pixels which cannot be reached by rays originating from the sun direction, due to topographic occlusion. The mask is applied to the illumination data so that the illumination equals zero in cast shadows.

\section{Methods}

\subsection{Atmospheric correction approaches}

According to (Verhoef \& Bach, 2003), the radiative transfer in the atmospheresurface system can be sufficiently approximated with the so-called four-stream theory comprising four spectral flux types. The fluxes considered are the downward solar flux, the diffuse downward flux, the diffuse upward flux and the upward spectral radiance in the direction of the observer. This study focuses exclusively on radiative transfer modelling approaches based on this theory to determine TOC hemispherical-directional reflectance factors (HDRF). To elaborate, irradiance is considered hemispherically while reflected radiances are measured by a sensor with a very small but non-zero IFOV (i.e., APEX IFOV is $\left.0.025^{\circ}\right)$. In theory this results in hemispherical-conical reflectance factors (HCRF). In practice, however, reflectances from such small IFOV measurements are generally referred to as HDRF to differentiate them from wide IFOV instrument results (cf. Schaepman-Strub et al., 2006, for details on terminology). Calibrated radiance data is processed to HDRF data using a simplified atmospheric correction approach compared to the state of the art atmospheric correction software ATCOR-4 (Richter \& Schläpfer, 2002, 2016). The simplified approach includes the complete four-stream radiative transfer calculations but excludes atmospheric parameter retrieval, spectral polishing, and radiometric fine tuning steps as implemented in ATCOR-4. We decided on a simplified atmospheric correction approach to ease evaluations and adjustments of atmospheric correction strategies. We also applied ATCOR-4 and used obtained HDRF as a reference 
to evaluate reliability of results stemming from the simplified atmospheric correction approach. In general, the atmospheric correction process can be divided into the following four steps: i) the simulation and storage of atmospheric transfer functions in look-up tables (LUT), ii) the estimation of spectral shifts and band broadening, iii) the convolution of the atmospheric functions considering the actual spectral sensor configuration, and iv) the calculation of HDRF values by combining measured at sensor radiances and simulated LUT entries. The simulation of atmospheric functions is performed for five different ground heights using MODTRAN5 (Berk et al., 2006) and the MODTRAN interrogation technique as introduced by Verhoef \& Bach (2003). Atmospheric variables water vapour and aerosol optical thickness (AOT), required to parameterize MODTRAN5, were chosen based on sun-photometer measurements from a close by AERONET station (Holben et al., 1998) and ATCOR-4 image-based retrievals. The simulation of combined atmospheric functions (e.g., combined downward and upward transmittances) was performed in this step to avoid violation of the Beer-Lambert law in subsequent calculations with convolved functions (Verhoef et al., 2014). The estimation of potential spectral misregistrations, also known as spectral smile, common to pushbroom spectrometers, and band broadening of APEX was performed with a method included in ATCOR-4 (Richter et al., 2011). Obtained spectral characteristics of APEX are used to generate spectral response functions to eventually convolve simulated atmospheric functions. The atmospheric correction approaches used in this study are listed in tab. (2). The method of simulating irradiance is varied in three steps of theoretically increasing accuracy. Each method requires a different set of auxiliary data as input. The first approach approximates irradiance variations using a coarse DEM and serves as a reference (DEMAC). The second approach follows the same procedure but uses a DOM to determine irradiance (DOMAC). Finally, the third approach utilizes irradiance scaling factors derived from top-of-canopy (TOC) irradiances simulated by the $3 \mathrm{D}$ Discrete Anisotropic Radiative Transfer (DART) model (Gastellu-Etchegorry et al., 2015) (DARTAC). The three methods are elaborated in the following sections. 
Table 2: Reference for the atmospheric correction approaches used, their acronyms and auxiliary data inputs from which irradiance is derived.

\begin{tabular}{|c|c|c|}
\hline Acronym & Input & Description \\
\hline ATCOR & DEM & $\begin{array}{l}\text { Atmospheric correction performed with the ATCOR- } 4 \\
\text { software }\end{array}$ \\
\hline DEMAC & DEM & $\begin{array}{l}\text { Simplified atmospheric correction procedure based on } \\
\text { four-stream theory }\end{array}$ \\
\hline DOMAC & DOM & Identical to DEMAC but using a DOM as input \\
\hline DARTAC & $\begin{array}{l}\text { parameterized } \\
\text { voxel grid }\end{array}$ & $\begin{array}{l}\text { Identical to DEMAC but utilizing DART derived irradiance } \\
\text { fraction maps as scaling factors }\end{array}$ \\
\hline
\end{tabular}

3.1.1. DEMAC: Simple atmospheric correction using a smoothed digital elevation model

Verhoef et al. (2014) have used the four-stream theory to simulate top-ofatmosphere (TOA) radiances using combined models (e.g., SCOPE (Van der Tol et al., 2009), and MODTRAN4). According to them, the radiative transfer through the atmosphere yielding TOA radiance for a target $\left(L_{T O A}\right)$ can be described as (eq . 1):

$$
\begin{aligned}
L_{T O A}= & \rho_{s o} \frac{E_{s}^{o} \cos \theta_{s}}{\pi} \\
& +\left[\frac{\tau_{s s} r_{s o} E_{s}^{o} \cos \theta_{s}}{\pi}+\frac{\left(\tau_{s d}+\tau_{s s} \overline{r_{s d}} \rho_{d d}\right) E_{s}^{o} \cos \theta_{s} / \pi}{1-\overline{r_{d d}} \rho_{d d}} r_{d o}\right] \tau_{o o} \\
& +\left[\frac{\left(\tau_{s d} \overline{r_{d d}}+\tau_{s s} \overline{r_{s d}}\right) E_{s}^{o} \cos \theta_{s} / \pi}{1-\overline{r_{d d}} \rho_{d d}}\right] \tau_{d o}
\end{aligned}
$$

Eq. (1) is formed by three additive terms including the atmospheric path radiance, the target's surface radiance, and the adjacency effect. The surface reflectance can be described by four terms: $r_{s o}$ is the bi-directional reflectance factor of the target $(\mathrm{BRF}), r_{d o}$ the hemispheric-directional reflectance factor of the target $(\mathrm{HDRF}), \overline{r_{s d}}$ is the smoothed directional-hemispherical reflectance factor 


$$
L_{T O A} \approx T_{1} T_{2}+\frac{T_{1}\left(T_{8} r_{s o} V_{s u n}+T_{9} r_{d o} V_{s k y}+T_{10} \overline{r_{s d}}+T_{11} \overline{r_{d d}}\right)}{1-\overline{r_{d d}} T_{3}}
$$

While $T_{n}$ represent atmospheric transfer functions (tab. 3), $\bar{r}$ indicate smoothed averaged reflectances and $V_{\text {sun }}, V_{\text {sky }}$ can be expressed as (eq. 3, eq. 4):

$$
\begin{gathered}
V_{\text {sun }}=\cos \theta_{t}+\tan \theta_{s} \sin \theta_{t} \cos \left(\varphi_{s}-\varphi_{t}\right) \\
V_{\text {sky }}=\frac{1+\cos \theta_{t}}{2}
\end{gathered}
$$

$V_{\text {sun }}$ and $V_{\text {sky }}$ are scaling factors that express in a simple way how the direct irradiance of the sun and the diffuse irradiance of the sky are changed by the local topography. $\theta_{t}$ is the terrain slope inclination, $\varphi_{t}$ the terrain slope azimuth, and $\varphi_{s}$ the solar azimuth angle. 
Table 3: Atmospheric functions and their abbreviations. Angled brackets represent convolved quantities.

\begin{tabular}{rc}
\hline Atmospheric function & Name \\
\hline$\left\langle E_{s}^{o}\right\rangle \cos \theta_{s} / \pi$ & $T_{1}$ \\
$\left\langle\rho_{s o}\right\rangle$ & $T_{2}$ \\
$\left\langle\rho_{d d}\right\rangle$ & $T_{3}$ \\
$\left\langle\tau_{s s}\right\rangle$ & $T_{4}$ \\
$\left\langle\tau_{s d}\right\rangle$ & $T_{5}$ \\
$\left\langle\tau_{o o}\right\rangle$ & $T_{6}$ \\
$\left\langle\tau_{d o}\right\rangle$ & $T_{7}$ \\
$\left\langle\tau_{s s} \tau_{o o}\right\rangle$ & $T_{8}$ \\
$\left\langle\tau_{s d} \tau_{o o}\right\rangle$ & $T_{9}$ \\
$\left\langle\tau_{s s} \tau_{d o}\right\rangle$ & $T_{10}$ \\
$\left\langle\tau_{s d} \tau_{d o}\right\rangle$ & $T_{11}$ \\
\hline
\end{tabular}

$$
\bar{r}=\frac{\overline{L_{T O A}}-T_{1} T_{2}}{T_{1}\left(T_{8}+T_{9}+T_{10}+T_{11}\right)+\left(\overline{L_{T O A}}-T_{1} T_{2}\right) T_{3}}
$$

Assuming a Lambertian Earth surface, reflectance quantities can be assumed similar (i.e., TOC reflectance $(r)=r_{\text {so }}=r_{d o}$ and TOC adjacent reflectance $(\bar{r})$ $=\overline{r_{s d}}=\overline{r_{d d}}$ ) so that one can rewrite eq. (2) to yield $r$ from the measured at-sensor radiance. However, since $\bar{r}$ is still unknown it must be estimated in two steps using a simplified version of eq. (2) where we assume a non-tilted, uniform Lambertian Earth surface and use filtered radiances $\left(\overline{L_{T O A}}\right)$ (eq. 5$)$. The employed kernel is sharply peaked towards the centre and was derived from the results of a Monte Carlo simulation of photon scattering, which allows a description of the adjacency effect by considering the contribution of photons from ring-shaped intervals of increasing distance to the target. Commonly, adjacency is estimated using only smoothed reflectance values (e.g. Richter, 1998). 
This finally allows a retrieval of $\mathrm{r}$ as follows (eq. 6):

$$
r=\frac{\left(L_{T O A}-T_{1} T_{2}\right)\left(1-\bar{r} T_{3}\right)-\bar{r} T_{1}\left(T_{10}+T_{11}\right)}{T_{1}\left(T_{8} V_{\text {sun }}+T_{9} V_{\text {sky }}\right)}
$$

This reflectance retrieval method is applied in combination with the smoothed DEM and further referred to as DEMAC.

\subsubsection{DOMAC: Simple atmospheric correction using a digital object model}

The smoothed DEM used in the DEMAC approach does not resolve single canopies and therefore can't be employed to describe the strongly varying irradiance at canopy scale. In order to do this we use a LiDAR based DOM instead. This effectively influences only the scaling factors $V_{\text {sun }}$ and $V_{\text {sky }}$ while the processing steps remain identical to DEMAC, reflectance being retrieved with eq. (6). The geometric surface description with a DOM has some limitations as it will yield $V_{\text {sun }}$ values of 0 for strongly inclined tree canopies with slopes facing away from the sun as well as for cast-shadows. While a complete lack of direct irradiance is unlikely in these situations, the assumption was deemed adequate for this experiment and resulting overestimates of HDRF taken into account. This reflectance retrieval approach is referred to further as DOMAC.

\subsubsection{DARTAC: DART radiance output approach}

The DART model (Gastellu-Etchegorry et al., 2015) is increasingly applied in vegetation analysis, for example as a tool to simulate at-sensor radiance data by parameterizing the model using LiDAR data (Schneider et al., 2014). The potential of such $3 \mathrm{D}$ radiative transfer modelling frameworks to derive accurate irradiance estimates has been suggested in previous work (Schläpfer et al., 2003). For our study site, LiDAR point cloud measurements were acquired by an ALS system close to the acquisition of APEX data. The point cloud was converted into a voxel grid and associated with different properties. A tree canopy voxel, for example, was assumed as turbid medium with certain leaf optical properties, 
plant area index (PAI) and a specific angular distribution of leaves (GastelluEtchegorry et al., 2015). For a detailed description of the parameterization of the 3D voxel grid, we refer to Schneider et al. (2014) and Schneider et al. (2015), while details on the DART simulation process can be found in GastelluEtchegorry et al. (2015). Due to computational constraints, only 24 scattering directions were used and a maximum of 3 iterations were performed. Direct and diffuse irradiances at TOC were derived from DART simulation outputs as $2 \mathrm{D}$ grids of irradiance in $W / \mathrm{m}^{2}$ for four wavelengths representing blue, green, red and NIR. The irradiance fractions per pixel (henceforth $K_{d i r}$ and $K_{\text {dif }}$ ) were derived relative to the maximum direct or diffuse irradiance, excluding outliers resulting from processing artefacts, and linearly interpolated for the wavelengths not simulated. For direct irradiance the scaling factors remain constant over all wavelengths, while for diffuse irradiance there are wavelength dependent differences. As the wavelengths used for further analysis lie close to the simulated wavelengths, this approximation is deemed sufficient. The fractions can be applied directly as scaling factors for the direct and diffuse fluxes to retrieve $r$ (eq. 7):

$$
r=\frac{\left(L_{T O A}-T_{1} T_{2}\right)\left(1-\bar{r} T_{3}\right)-\bar{r} T_{1}\left(T_{10}+T_{11}\right)}{T_{1}\left(T_{8} K_{d i r}+T_{9} K_{d i f}\right)}
$$

This approach is further referred to as DARTAC.

\subsection{Field spectrometer measurements}

Two ASD field spectroradiometer (ASD FieldSpec, Analytical Spectral Devices, USA) measurements acquired during the 2010 APEX validation campaign in Wettingen, Switzerland were used as ground-truth data for this study. The measured spectra allow an evaluation of the atmospheric correction method's performance. The reference surfaces were selected based on uniformity of the target, lack of inclination and are pseudo-invariant features. The surfaces are yellow tartan of the Wettingen sports-ground $\left(47^{\circ} 28^{\prime} 02.30 " N 8^{\circ} 18^{\prime} 33.90^{\prime \prime} \mathrm{E}\right)$ and 
a black roof of the swimming baths $\left(47^{\circ} 27^{\prime} 58.84^{\prime \prime} \mathrm{N} 8^{\circ} 18^{\prime} 38.86^{\prime \prime} \mathrm{E}\right)$ which showed near uniform reflectance over all wavelengths. The measurements were conducted close to acquisition time for both dates and perpendicular to the surfaces.

\subsection{Deriving vegetation indices}

A number of vegetation indices were derived from TOC reflectance data to evaluate the impact of irradiance effects and their compensation using the three approaches under evaluation. The use of vegetation indices is an empirical approach to relate light measurements to vegetation information. Even if properly calibrated for a specific site, vegetation type and phenological period, wrong estimates of surface irradiance pose an additional sensitivity to these indices and complicate their interpretation. We focus our choice on indices that incorporate spectral information from the VIS/NIR wavelength regions since they are more strongly affected by illumination effects and estimated errors can serve as worst case scenarios. Calculated indices include the NDVI, commonly used as a proxy for canopy chlorophyll content and fAPAR (Tucker, 1979) (eq. 8) and the PRI, indicative for the de-epoxidation state of xanthophylls and often applied as proxy for LUE (Gamon et al., 1992, 1997) (eq. 9). Further, we applied two indices sensitive to the relative content of chlorophyll and carotenoids as proposed by (Gitelson et al., 2006) (eq. 10 and 11).

$$
\begin{gathered}
N D V I=\frac{r_{800}-r_{640}}{r_{800}+r_{640}} \\
P R I=\frac{r_{531}-r_{570}}{r_{531}+r_{570}} \\
C H L \propto\left[r_{540-560}^{-1}-r_{790}^{-1}\right] \times r_{790} \\
C A R \propto\left[r_{510-520}^{-1}-r_{560-570}^{-1}\right] \times r_{790}
\end{gathered}
$$


Subscripts in eq. 10 and eq. 11 indicate wavelength ranges in nanometer used for the calculation of both indices. Gitelson et al. (2006) provide two models each for CHL and CAR, one incorporating green wavelengths and the other the red edge. We use the mean values over the proposed green wavelength ranges here as they should be more susceptible to differences in irradiance composition.

\subsection{Assessment of irradiance effects on vegetation indices}

The performance of the DEMAC, DOMAC and DARTAC approaches for the removal of illumination effects in vegetation products is evaluated by comparing obtained index values with reference values representing fully illuminated cases. We set up two tests, the first evaluating the performance of the three approaches in cast-shadows, the second focussing on a forest subset. For the cast-shadow test, a number of areas were chosen and divided into sparsely and densely vegetated surfaces. "Sparsely" vegetated surfaces are surfaces with very low vegetation fraction (e.g. below 10\%), close to bare-soil. "Densely" vegetated surfaces have a vegetation cover of $100 \%$. It must be noted that slight changes in the species composition are possible for sparsely vegetated surfaces. We assume, however, that these changes are negligible and do not impact our results. The reference value is extracted over horizontal, fully illuminated areas of the same surface type in the DEMAC result. For the forest test, reference values represent the mean of horizontal oriented and fully illuminated areas (tops of tree canopies) extracted from the DEMAC result. For both tests, mean values of pixel-wise absolute differences between the index and the reference mean value are calculated. The pixel-wise differences are used in order to reflect heterogeneity in the result. Pixel values outside of physically feasible ranges are omitted. Finally, the improvement of the DOMAC and DARTAC approaches over the DEMAC approach is expressed as percentage by which the difference of the index to the reference value for the DEMAC approach could be reduced with either the DOMAC or DARTAC approach. The significance of this difference is assessed using a paired t-test with $95 \%$ significance level $(p<<0.05)$. 


\section{Results}

\subsection{DEMAC in comparison with ATCOR}

An evaluation of DEMAC with ATCOR-4 was performed to confirm its suitability for further analysis. We particularly compared derived HDRF obtained from both approaches for two acquisition dates of pseudo-invariant features and related them to surface HCRF measurements obtained with a field spectroradiometer (ASD FieldSpec, Analytical Spectral Devices, USA). The results for one such surface are displayed in (fig. 2). For both the 26th and the 29th of June 2010, the mean difference in percent over all bands between DEMAC and ATCOR-4 is around $16 \%$ on average. Considering ASD measured HCRF, the DEMAC approach differs by $8.7 \%$ for the 26 th of June and $23.2 \%$ for the 29 th of June. ATCOR-4 HDRF values differ from ASD measurements by $9.2 \%$ for the 26th and $5.0 \%$ for the 29th. Comparisons of HCRF with HDRF should be made with caution as they represent different physical quantities. Furthermore, the deviations between solar zenith angles during APEX and ASD acquisitions are up to $20^{\circ}$. The mean difference in percent between ATCOR-4 based HDRF for the two days is $14.5 \%$ while this difference is $13 \%$ for DEMAC. It is possible that this variation can be partly explained by the difference in solar zenith angle in combination with reflectance anisotropy effects. Absolute deviations of obtained HDRF values between DEMAC and ATCOR-4 are not detrimental for subsequent analysis. However, some differences appear to be wavelength dependent. ATCOR-4 results appear more robust over wavelengths, while the DEMAC results fit better with each other and to the ASD spectrum in the 500-600 $\mathrm{nm}$ range but deviate more in the NIR. The precise reason, especially for the deviation in the NIR, could not be identified, but there are two differences between the DEMAC approach and ATCOR-4 that likely explains observed differences: i) ATCOR-4 uses the horizon algorithm providing a more accurate value for $V_{s k y}$ than the slope based calculation used in DEMAC. ii) In the chosen ATCOR-4 configuration, atmospheric conditions are specified with a constant AOT across the scene but varying water vapour over the image, and 
viewing angle dependent scattering functions for the correction of aerosol effects were used. In DEMAC, atmospheric parameters were obtained from AERONET and ATCOR-4 and only distributed considering ground and sensor height. The compensation of adjacency effects was evaluated by observing the averaged HDRF of a black rooftop (height $5 \mathrm{~m}$ ) (fig. 3). ASD measurements suggest a spectrally featureless reflectance behaviour with average values of $5 \%$. The rooftop is located in a valley situation and is surrounded by vegetation (trees and vegetated mountains). Scattering of adjacent vegetation surfaces would add a signal to the almost non-reflective roof-top contribution if not adequately corrected. There are no remnants of any vegetation signals visible in obtained HDRF spectra and barring a very slight slope towards NIR wavelengths, the adjacency effect compensation appears to be sufficient. It must be noted that HDRF values resulting from DEMAC were not smoothed or interpolated as is done in ATCOR-4, resulting in the visible spikes in the spectrum; differences attributed to this were deemed negligible. The spikes originate from residual errors in estimated spectral shift and band broadening. If such spectral information is used to convolve atmospheric functions to match the in-flight spectral setting of the sensor, spikes typically occur across strong atmospheric or solar absorption lines. Despite certain deviations between HDRFs obtained from ATCOR-4 and our implementation, for the evaluated situations the DEMAC procedure was deemed to perform within sufficient accuracy which is comparable to a more complex correction scheme in common use. 

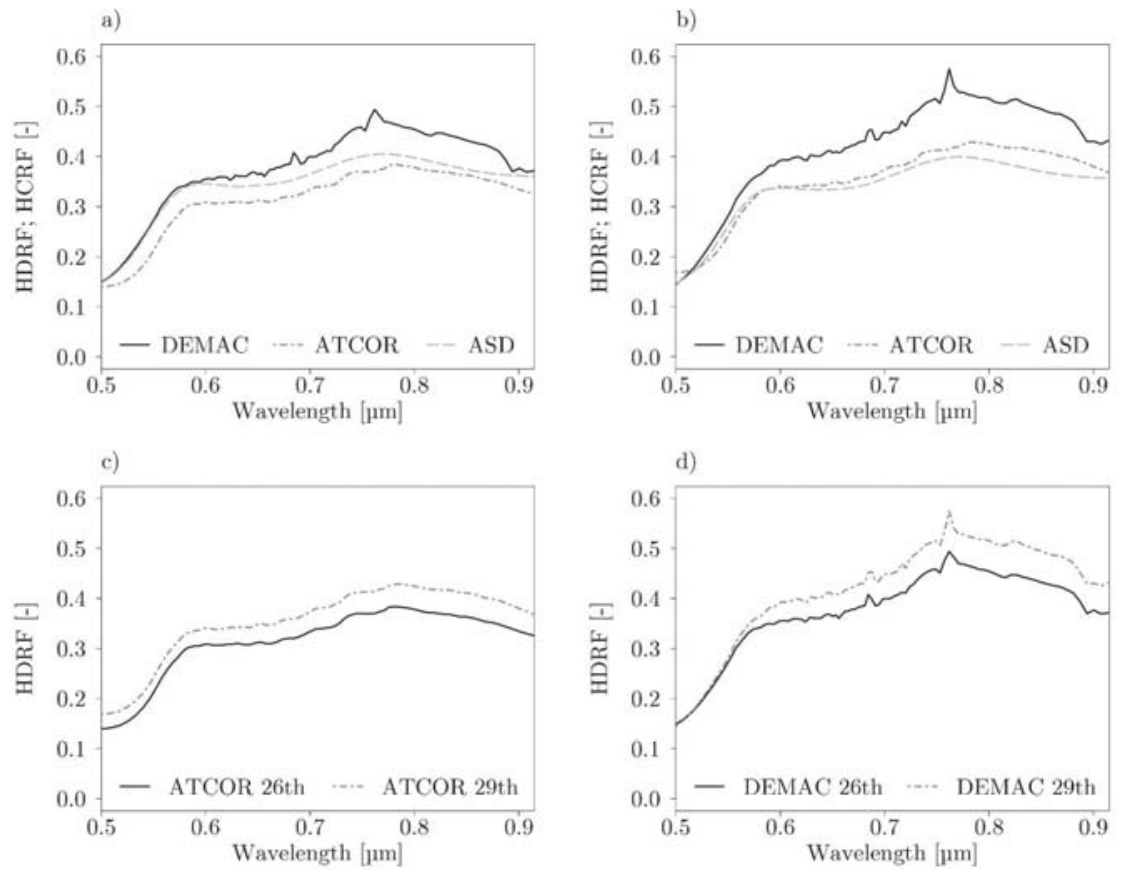

Figure 2: Comparison of reflectance spectra of a yellow tartan sports-surface, resulting from ASD measurements (HCRF), the DEMAC approach (HDRF), and the ATCOR-4 processing (HDRF). a) 26.06.2010 dataset. b) 29.06.2010 dataset. c) ATCOR-4 result comparison between the two dates. d) DEMAC comparison between the two dates. It must be noted that results for the DEMAC and DOMAC approach are identical for flat surfaces such as the investigated tartan. 


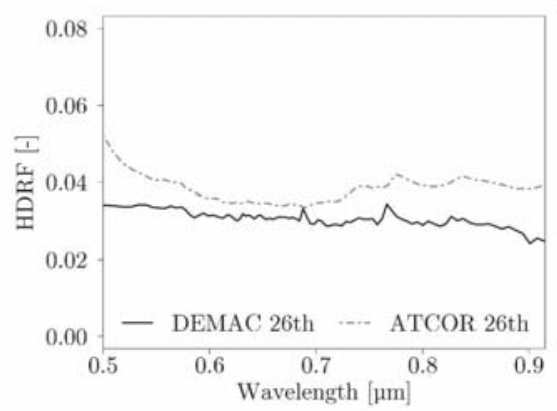

Figure 3: Comparison of HDRF spectra averaged over a dark, spectrally uniform reflecting roof for the DEMAC approach and the ATCOR-4 processing, both for the 26.06.2010 dataset.

\subsection{Improvement of reflectance retrieval with digital object models}

The evaluated DOMAC approach incorporating a DOM to improve irradiance estimates by considering crown geometry yields diverse results. Shaded canopy areas show overestimates of obtained HDRF values (above 100\% reflectance) (fig. 4). This is mainly since $V_{\text {sun }}$ approaches 0 and due to the large slope angle $\left(\cos \theta_{t}\right)$ for such canopy areas, the diffuse component is also heavily reduced through $V_{\text {sky }}$. For sunlit canopy areas, HDRF differences are reduced. This observation could be confirmed also for a large forest canopy subset, where small slope angles yielded improved corrections and steep angles led to overcorrections. 

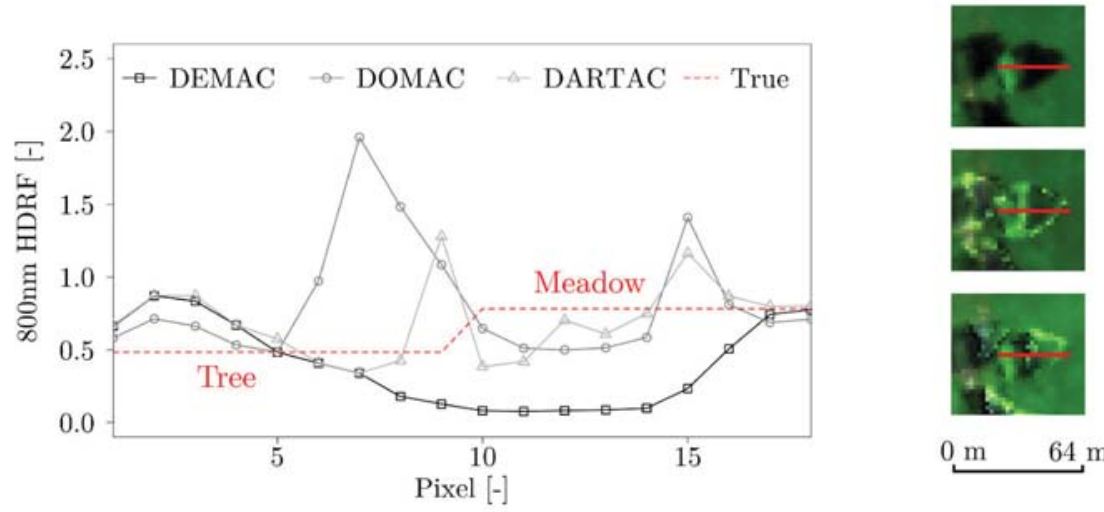

Figure 4: Left: HDRF at $800 \mathrm{~nm}$ along a tree-crown to meadow cast-shadow transect (left to right) resulting from DEMAC, DOMAC and DARTAC. The red dashed line indicates the expected true HDRF along the transect for the tree and meadow surfaces. Right: Illustration of the transect for the DEMAC, DOMAC and DARTAC based results as true colour RGB images (top to bottom). The red line indicates the transect as shown in the left figure.
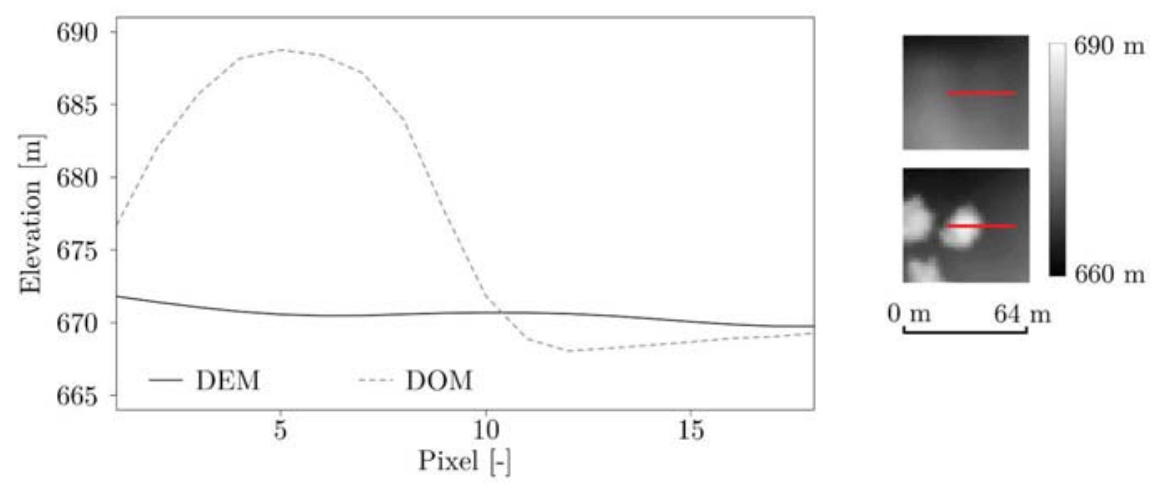

Figure 5: Left: Surface elevation along a tree-crown to meadow cast-shadow transect for the smoothed digital elevation model (DEM) and the digital object model (DOM). Right: Image representation of the smoothed DEM (top) and DOM (bottom). The red line indicates the transect as shown in the left figure.

While an offset remains, areas affected by cast-shadows experience an improved correction of illumination effects when compared to fully illuminated 
regions, as also visible in the transect of fig. 4 and the region of interest (ROI) comparison of fig. 6. Exceptions are transition zones from fully illuminated to fully shaded areas, visible as spikes in the transect (fig. 4). The observed effect is caused by a complex interplay of different factors, including residual geometric co-registration errors between the DOM and the spectroscopy data, the simplified radiative transfer scheme applied that neglects vertical radiation entering the surface, as well as canopy transparency at the outer crown leading to a very uneven illumination pattern in the transition zone of cast shadow and full illumination i.e. mixture of sun flecks and shade. The percentage deviation of retrieved HDRF in cast-shadows from illuminated areas was calculated. The DEMAC-illuminated pixels with little to no slope are considered as reference under the assumption that these are closest to the sought surface reflectance under illuminated conditions, as the surface covered by these pixels receives full direct and diffuse illumination. DEMAC-shade and DOMAC-shade belong to pixels of shaded vegetated surfaces. Since the DEM approach does not resolve canopy topography (see fig. (5)), the approach assumes full illumination for these cast-shadow pixels although they predominantly receive diffuse irradiance. This yields an underestimation of retrieved reflectance because irradiance is overestimated $(L / E)$. Conversely, the use of a DOM provides an improved estimate of $E$, thus retrieved reflectance is closer to the reflectance of the fully illuminated surface. The deviation of HDRF between illuminated and shaded ROIs decreased on average over all bands from $86.4 \%$ for DEMAC to $37.5 \%$ for the DOMAC approach. There are still deviations between calculated means of up to $56.55 \%$, mainly around $700 \mathrm{~nm}$. Finally, the spatial difference between illuminated reference and shaded ROIs guarantee variance but this was considered during selection and kept as small as possible. 

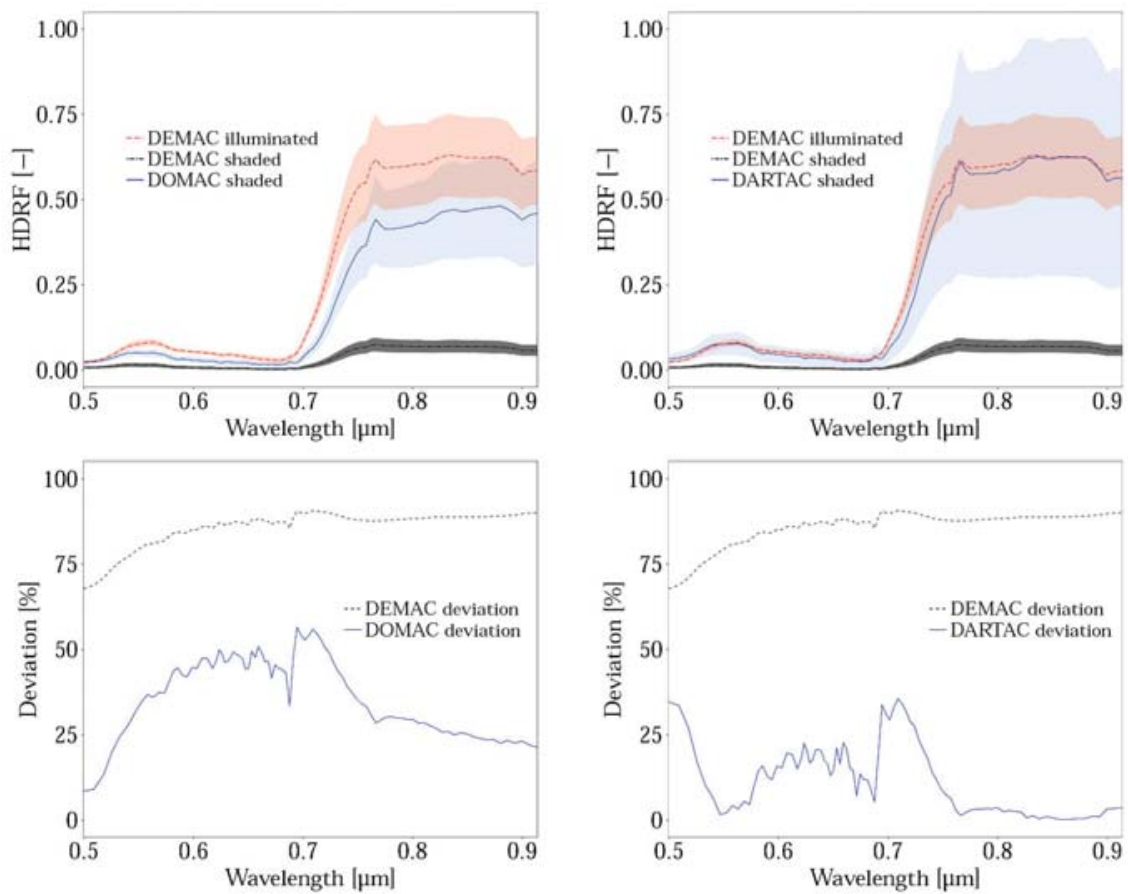

Figure 6: Top: HDRF of shaded surfaces before and after correction. Left: HDRF from the DEMAC approach averaged over fully illuminated regions of interest (ROIs) on highly vegetated surfaces (illuminated), HDRF obtained from the DEMAC approach over cast-shadow ROIs on highly vegetated surfaces (shaded), corrected HDRF from the DOMAC approach averaged over the same cast-shadow ROIs (shaded corr), and the ribbons representing mean \pm one standard deviation for each spectrum. Right: the same as left but with the correction from the DARTAC approach. Bottom: Deviation in percent of the cast-shadow reflectances in respect to the fully illuminated case. Left: Deviation of the DEMAC HDRF and the DOMAC HDRF. Right: the same as left but for DARTAC.

\subsection{Improvement of reflectance retrieval with simulated irradiance fractions}

Using scaling factors derived from DART simulations to adjust estimates of diffuse and direct irradiance components in atmospheric correction approaches should in theory provide benefits over the DOMAC approach: They are raytracing based which allows accounting for multiple scattering within the canopy. Indeed, we observe fewer overestimates of HDRF values over tree canopies in DARTAC results, but reflectance gradients seem to have been conserved for the 
most part (fig. 4). Evaluating corrected HDRF values at $800 \mathrm{~nm}$ over a forest subset, there appear to be generally lower reflectances compared to the DEMAC with a number of single pixels showing seemingly arbitrary high reflectance. These over estimated HDRF values are associated with the aforementioned gaps between trees where both direct and diffuse irradiance drop to near zero. We did not find a significant correction of shadowing effects across the tree canopies. Overestimated HDRF values are mainly visible in transition zones from shade to full illumination, where we observe a spatial mismatch between simulated and actual cast-shadows in the order of up to two pixels $(4 \mathrm{~m})$ in the most extreme cases, as well as for small gaps between trees in the forest. The cast-shadow transect (fig. 4) reveals a spike where the simulated shadow extends further than the actual shadow but the difference between shaded and illuminated pixels is clearly reduced. In the ROI comparison, we found a far larger heterogeneity with small scale over and under corrections of HDRF values. When averaged, their reflectance is comparable to fully illuminated counterparts (fig. 6). Averaged over all bands, the deviation in percentage from illuminated areas to corrected shaded counterparts has decreased to $9.6 \%$ when using DARTAC. The highest deviation between the averages is $35.5 \%$ and is observable at the red-edge.

\subsection{Vegetation indices}

Results for the evaluation of correction approaches for all vegetation products are presented in tab. (4) and tab. (5) for the cast-shadow test and for the forest test in tab. (6). Differences between index and reference values larger than for the DEMAC case result in negative percentages for "Diff reduced" while an equal difference corresponds to $0 \%$ and a full reduction of differences and therefore a perfect match of index with reference values corresponds to $100 \%$. A paired t-test with $95 \%$ significance level indicates that mean values of all DOMAC and DARTAC results are significantly different from the DEMAC result. Fig. (7) illustrates results for a subset of the scene containing a heterogeneous vegetation cover and illumination conditions, while Fig. (8) depicts the spatial differences from the DEMAC results as well as images of the direct illumination and DOM 
for reference.

\section{NDVI}

The difference in NDVI between shaded and fully illuminated areas is very small for both dense and sparse vegetation cover. Applying both, the DOMAC and the DARTAC approach yields overestimated NDVI values in cast-shadow.

For densely vegetated surfaces this is a slight overestimation, leading to a reduction of the difference by $8.6 \%$ for DARTAC and next to no change for DOMAC. For sparse vegetation the overestimation is more extreme, leading to values deviating more from the illuminated reference ( $47.9 \%$ and $39.6 \%$ increase). For the forest subset, both approaches do not yield any improvement and DOMAC results show a $14.9 \%$ increased difference.

PRI

For the PRI, differences between shaded and fully illuminated areas are large for dense and sparse vegetation cover. Applying both, the DOMAC and the DARTAC approach yields slightly overestimated PRI values in cast-shadow. The reduction of illumination effects is considerable: for sparse vegetation the improvement is between $43.8 \%$ for the DOMAC approach and $65.7 \%$ for the DARTAC approach. A similar picture can be observed for dense vegetation. For the forest subset, the DOMAC approach slightly reduces uncertainties while the DARTAC approach yields results close to the DEM result.

Chlorophyll index

Both, the DOMAC and the DARTAC approach yield consistent improvements of CHL estimates compared to the DEMAC approach of 38.9 to $71.0 \%$ for cast-shadows in sparse and dense vegetation. Of note is however that the DARTAC approach increases the standard deviation considerably. The DOMAC approach shows higher consistency across surface types. The improvements for cast-shadows are clearly visible in Fig. (9), however, trees display an overestimation of retrieved chlorophyll content in the DOMAC result (difference to reference is increased by $84.5 \%$ ). For the DARTAC approach, chlorophyll is 
slightly underestimated.

\section{Carotenoid index}

Retrieved carotenoid contents in cast-shadow show significant improvements for both approaches. Improvements are consistently above $40 \%$ with DARTAC performing the best for sparsely vegetated areas with $52.2 \%$. Here mean values are much closer to the reference but the standard deviation is clearly increased, accounting for the medium reduction overall. For the forest subset there is no notable change regarding the pixel-wise differences from the reference value.

Table 4: Impact of illumination effects on NDVI, PRI, chlorophyll and carotenoid index retrievals for densely vegetated surfaces. Index values in cast-shadow and fully illuminated areas were compared. The compensation of illumination effects using three atmospheric correction strategies (DEMAC, DOMAC and DARTAC approaches) was evaluated. Calculated statistics include mean, standard deviation, mean pixel-wise absolute difference to the illuminated reference value and percent reduction of this difference in respect to the DEMAC case.

\begin{tabular}{|c|c|c|c|c|c|}
\hline & & Mean & StDev & Abs Diff & $\begin{array}{l}\% \text { Diff } \\
\text { reduced }\end{array}$ \\
\hline \multirow[t]{4}{*}{ NDVI } & Reference & 0.863 & 0.039 & - & - \\
\hline & DEMAC & 0.860 & 0.057 & 0.046 & - \\
\hline & DOMAC & 0.900 & 0.042 & 0.046 & -0.2 \\
\hline & DARTAC & 0.890 & 0.044 & 0.042 & 8.6 \\
\hline \multirow[t]{4}{*}{ PRI } & Reference & -0.012 & 0.014 & - & - \\
\hline & DEMAC & 0.109 & 0.024 & 0.121 & - \\
\hline & DOMAC & 0.061 & 0.024 & 0.074 & 39.4 \\
\hline & DARTAC & 0.053 & 0.030 & 0.067 & 44.9 \\
\hline \multirow[t]{4}{*}{ CHL } & Reference & 6.536 & 1.219 & - & - \\
\hline & DEMAC & 3.678 & 1.202 & 2.912 & - \\
\hline & DOMAC & 7.300 & 2.208 & 1.778 & 38.9 \\
\hline & DARTAC & 6.448 & 1.837 & 1.504 & 48.3 \\
\hline \multirow[t]{4}{*}{ CAR } & Reference & 7.435 & 2.137 & - & - \\
\hline & DEMAC & 1.541 & 0.575 & 5.893 & - \\
\hline & DOMAC & 4.222 & 1.357 & 3.249 & 44.9 \\
\hline & DARTAC & 4.045 & 1.445 & 3.393 & 42.4 \\
\hline
\end{tabular}


Table 5: Impact of illumination effects on NDVI, PRI, chlorophyll and carotenoid index retrievals for sparsely vegetated surfaces. Index values in cast-shadow and fully illuminated areas were compared. Statistics are described in tab. 4

\begin{tabular}{|c|c|c|c|c|c|}
\hline & & Mean & StDev & Abs Diff & $\begin{array}{l}\% \text { Diff } \\
\text { reduced }\end{array}$ \\
\hline \multirow[t]{4}{*}{ NDVI } & Reference & 0.489 & 0.032 & - & - \\
\hline & DEMAC & 0.450 & 0.069 & 0.063 & - \\
\hline & DOMAC & 0.579 & 0.058 & 0.093 & -47.9 \\
\hline & DARTAC & 0.572 & 0.070 & 0.088 & -39.6 \\
\hline \multirow[t]{4}{*}{ PRI } & Reference & -0.063 & 0.009 & - & - \\
\hline & DEMAC & 0.039 & 0.024 & 0.103 & - \\
\hline & DOMAC & -0.006 & 0.022 & 0.058 & 43.8 \\
\hline & DARTAC & -0.030 & 0.023 & 0.035 & 65.7 \\
\hline \multirow[t]{4}{*}{ CHL } & Reference & 2.226 & 0.232 & - & - \\
\hline & DEMAC & 0.815 & 0.294 & 1.411 & - \\
\hline & DOMAC & 2.127 & 0.498 & 0.409 & 71.0 \\
\hline & DARTAC & 2.279 & 0.777 & 0.563 & 60.1 \\
\hline \multirow[t]{4}{*}{ CAR } & Reference & 1.071 & 0.207 & - & - \\
\hline & DEMAC & 0.101 & 0.104 & 0.970 & - \\
\hline & DOMAC & 0.592 & 0.194 & 0.491 & 49.3 \\
\hline & DARTAC & 0.979 & 0.561 & 0.464 & 52.2 \\
\hline
\end{tabular}


Table 6: Impact of illumination effects on NDVI, PRI, chlorophyll and carotenoid index retrievals for a forest canopy. Index values in inclined and flat, fully illuminated areas were compared. Statistics are described in tab. 4.

\begin{tabular}{llllll}
\hline & & Mean & StDev & Abs Diff & $\begin{array}{l}\text { \% Diff } \\
\text { reduced }\end{array}$ \\
\hline \multirow{2}{*}{ NDVI } & Reference & 0.904 & 0.020 & 0.000 & 0.0 \\
& DEMAC & 0.902 & 0.026 & 0.015 & 0.0 \\
& DOMAC & 0.910 & 0.024 & 0.018 & -14.9 \\
& DARTAC & 0.900 & 0.026 & 0.016 & -1.8 \\
\hline \multirow{2}{*}{ PRI } & Reference & -0.013 & 0.016 & 0.000 & 0.0 \\
& DEMAC & -0.002 & 0.031 & 0.021 & 0.0 \\
& DOMAC & -0.014 & 0.026 & 0.019 & 13.0 \\
& DARTAC & 0.000 & 0.028 & 0.021 & 3.5 \\
\hline \multirow{2}{*}{ CAR } & Reference & 9.146 & 1.654 & - & - \\
& DEMAC & 8.981 & 1.657 & 1.297 & - \\
& DOMAC & 10.645 & 3.058 & 2.393 & -84.5 \\
& DARTAC & 8.738 & 1.801 & 1.401 & -8.0 \\
\hline & Reference & 9.253 & 1.674 & - & - \\
& DEMAC & 8.107 & 2.593 & 2.109 & - \\
& DOMAC & 9.805 & 2.958 & 2.171 & -3.0 \\
& DARTAC & 7.696 & 2.377 & 2.148 & -1.9 \\
\hline
\end{tabular}


DEMAC
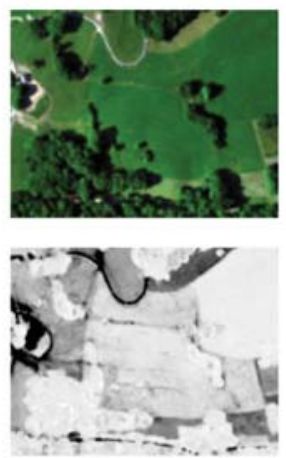

PRI

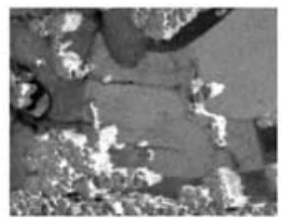

CHL

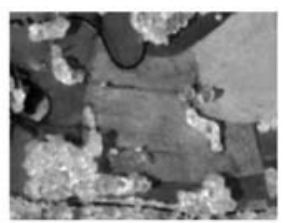

CAR
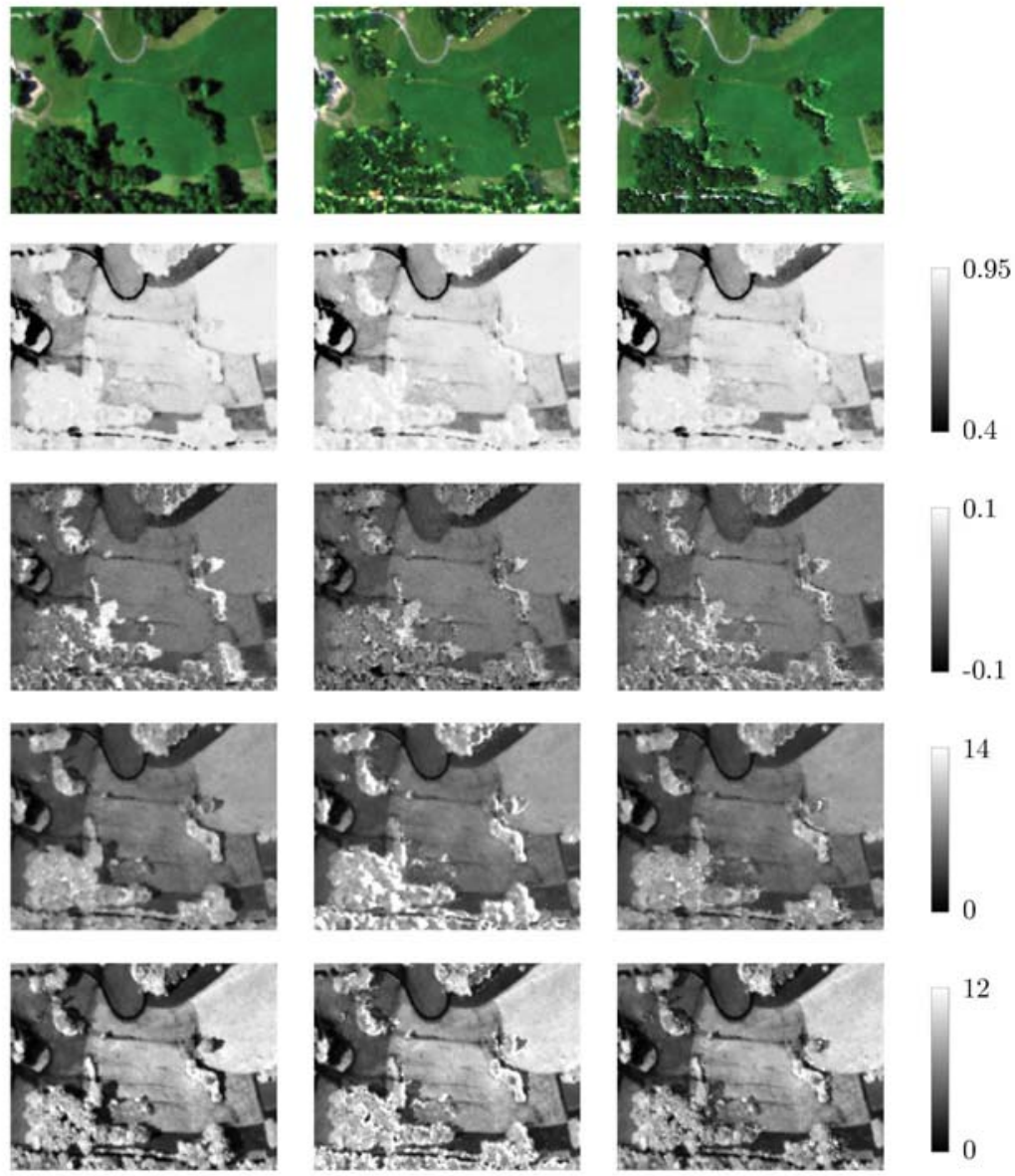

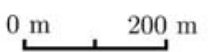

Figure 7: Impact of illumination effects on HDRF data and subsequently calculated vegetation indices. Results indicate the impact and compensation considering three different atmospheric correction approaches. Displayed are the true colour RGB representations and vegetation products (NDVI, PRI, chlorophyll and carotenoid indices) for a subset of the scene including fields, trees and cast-shadows. Shadows are visible as dark patches in the DEMAC RGB depiction. 
Illumination

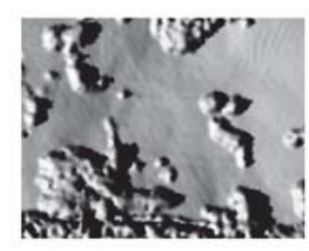

DOMAC - DEMAC
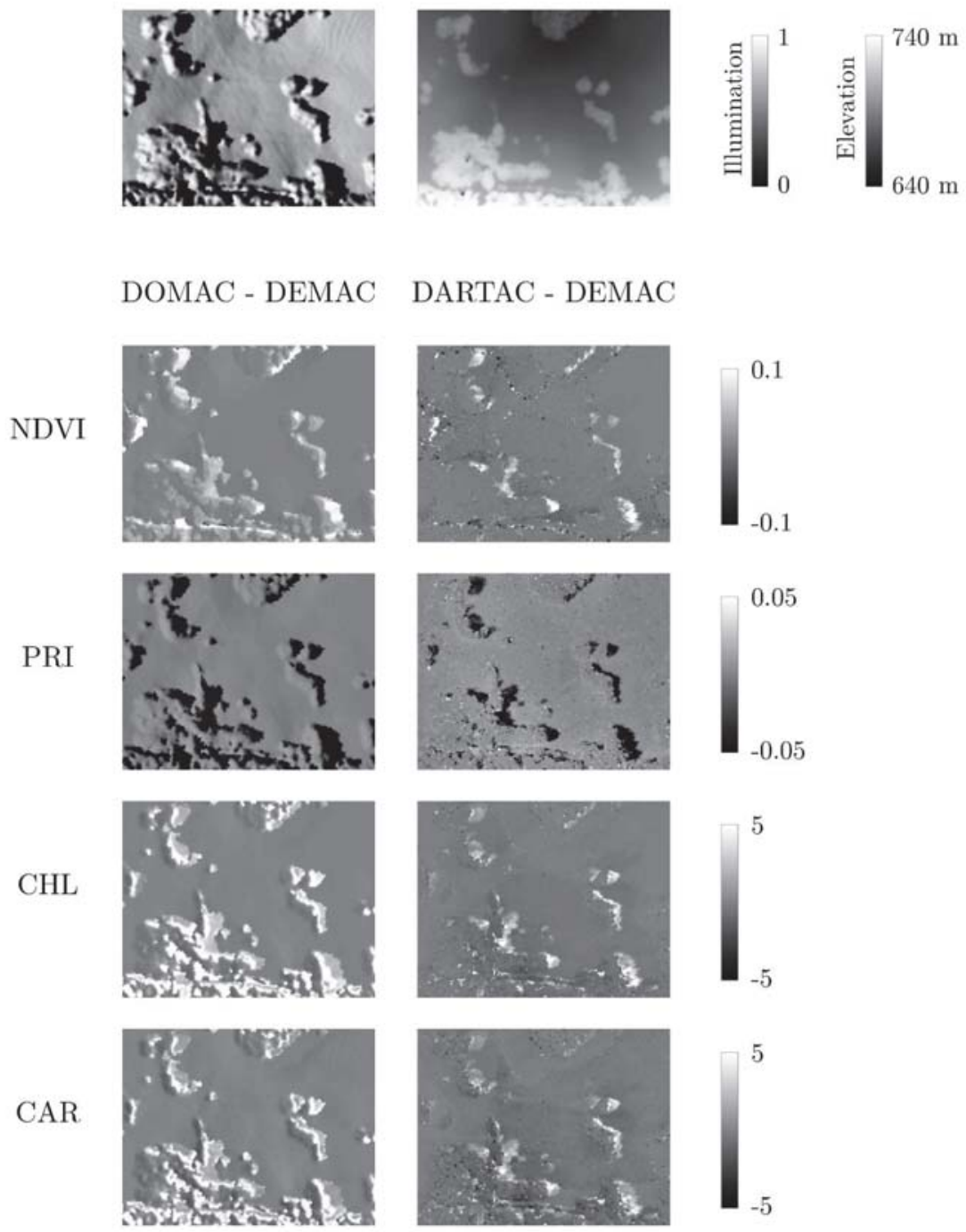

DARTAC - DEMAC
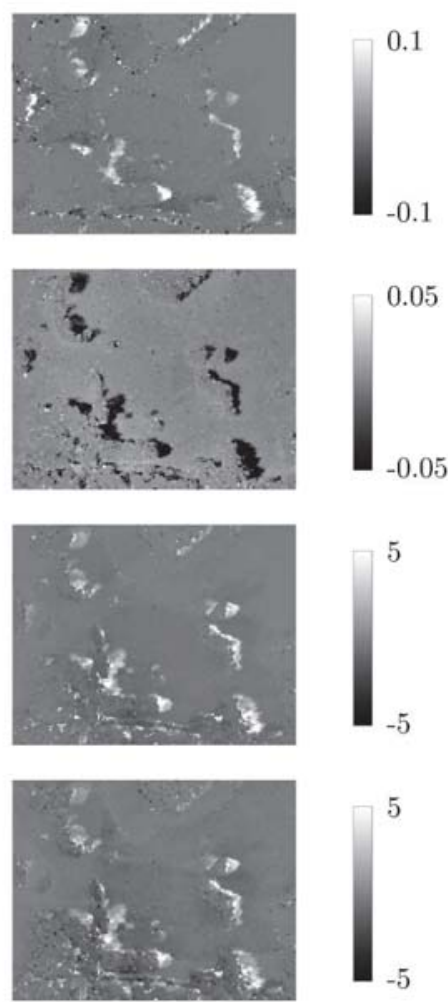

\section{$0 \mathrm{~m}, 200 \mathrm{~m}$}

Figure 8: Top: Illumination map (relative direct illumination, with cast-shadow pixels in black) and digital object model (DOM) of the test scene. Bottom: Difference maps of vegetation indices derived from the DOMAC and DEMAC (left) and DARTAC and DEMAC approach (right). 


\section{Discussion}

\subsection{Capability to advance estimates of direct and diffuse irradiance}

Simple atmospheric correction approaches typically assume flat Earth surfaces or coarsely approximate topography with smoothed DEMs and need minimal inputs to calculate reflectance (e.g. Ouaidrari \& Vermote, 1999; Richter, 1990). These approaches are not suitable for high resolution imagery and complex terrain. In early approaches seeking to compensate terrain influences, the cosine correction based on $\cos \theta_{i l}$ is applied (often directly to TOA radiances), using a DEM (Teillet et al., 1982). However, it was observed to be unsuitable for terrain containing steep inclines where the solar incident angle approaches $90^{\circ}$ or above (Itten \& Meyer, 1993; Teillet et al., 1982). Results of our DEMAC approach show no extreme underestimation of surface irradiance due to the use of a smoothed DEM. This strategy eliminates abrupt changes in geometry and diffuse irradiance estimates in relation to $\cos \theta_{t}$. However, since the DEM does not include single canopy geometries, correct irradiance values for tree crowns and cast-shadows cannot be estimated. Small-scale illumination based HDRF variations persist. The use of DOM's theoretically provides more accurate irradiance estimates since complex canopy geometry can be considered. In our experimental analysis, we however faced several difficulties and less consistent results than expected. HDRF in shaded parts of tree canopies was strongly overestimated due to an underestimation of irradiance, rendering an inherent problem in the DOM's 2.5-dimensional smooth description of canopy surfaces (Schläpfer et al., 2003). In regions with steep slopes, direct irradiance tends toward zero while diffuse irradiance is also reduced due to the slope. Overestimates of HDRF due to geometric effects have been observed in other studies and put down to inadequate spatial resolution of the DEM used (Sandmeier \& Itten, 1997). It is possible that the effect could be partly counteracted in our case by a DOM resolution which is slightly higher $(1 \mathrm{~m})$ compared to the pixel size of the image data $(2 \mathrm{~m})$. We expect that remaining effects are mainly caused by the fact that the canopies' 3-dimensional structure (e.g., leaf orientation) 
is insufficiently represented. The binary nature of the applied cast-shadow mask causes an under estimation of the direct irradiance. Despite this we still observe an underestimation of reflectance in the result for most cast-shadows. This can be explained by the fact that flat surfaces receive an overestimated amount of diffuse irradiance due to the slope-based calculation. The whole hemisphere is considered when in fact a large part of it is obscured by the trees casting the shadow. Simply omitting all diffuse irradiances from these directions would however in turn ignore multiple scattering effects from neighbouring canopies. It is likely that the combination of these effects cause the observed deviations between the corrected and illuminated reference regions. Moreover, direct and diffuse irradiance gradients in tree-canopy cast-shadows are not well understood and warrant further study. Irradiance estimates using 3D radiative transfer models such as DART was judged to be the most adequate strategy to account for the complex 3D architecture of forest canopies. Surprisingly, illumination patterns in DARTAC HDRF data persisted and strong over and underestimates of irradiance partially occurred. The insufficient correction of irradiance effects can be mainly attributed to the voxel size being too large to accurately approximate the canopy shape, especially as there is no slope information to scale irradiance in this approach. The voxel size of $2 \times 2 \times 2 m$ corresponds to the image pixel size of $2 \times 2 m$ but ideally the resolution used for the radiative transfer simulation would be higher and up-scaled to sensor resolution (Malenovský et al., 2007). Concerning the large uncertainties when finally deriving HDRF products, primarily the irradiance scaling factors as obtained from DART are the underlying cause: DART simulations were limited in their complexity due to computation time constraints. The spatial distribution of resulting diffuse scaling factors display a considerable deviation from the expected spatial distribution as obtained for direct irradiance. This kind of spatial mismatch is caused by an insufficient number of possible scattering directions during the simulation. A full convergence of diffuse and direct cast-shadows requires several hundreds to thousands of scattering directions in $4 \pi$ space (as opposed to the 24 used in this study), requiring considerable processing power and time. Studies using DART to si- 
mulate RS data of smaller scenes use 100+ angles (Gastellu-Etchegorry et al., 1996; Schneider et al., 2014). An efficient method to improve the simulation of canopy multiple scattering is an oversampling of certain angular regions, for example of the hot-spot configuration (Yin et al., 2013).

5.2. Reducing irradiance-based variation in vegetation indices using advanced atmospheric correction

Spectral vegetation indices derived over complex structured forest ecosystems can be subject to substantial illumination effects. The evaluated DOMAC and DARTAC approaches yield in general more reliable HDRF and index information but results are diverse. This diversity is mainly associated with the difficulty to accurately estimate shadow fractions and the wavelength dependency of illumination effects. For cast shadow where the actual fraction of direct irradiance can be reliably constrained, the DOMAC approach leads to most vegetation index products being significantly less sensitive to the illumination differences in cast-shadow, by roughly $50 \%$. An exception is the NDVI, which involves signals in the NIR that were affected by uncertainties in the estimation of direct irradiance. The main conceptual difference in forest canopies is that surfaces receiving purely diffuse irradiance are rare and, at the $2 m$ spatial scale investigated, varying amounts of direct and diffuse irradiance are actually present. Consequently, the overall differences between the reference case and DEMAC values at varying illuminations are much smaller. The correction results appear to be more diverse, which can be explained by the increasing uncertainty in actual irradiance estimates in combination with a wavelength dependency of this uncertainty. While no correction effect was found for the CAR index, the evaluated DOMAC approach shows spatially more consistent vegetation index values across canopies for PRI but slightly worse results for NDVI and substantially worse for CHL. The calculation of PRI incorporates wavelength regions in the visible strongly affected by fractional changes of direct and diffuse irradiance. The applied corrections seem overall to slightly improve HDRF retrievals at these wavelengths, possibly stemming from the DOMAC 
inclined surfaces leading to a better representation of the actual diffuse irradiance field. The calculation of NDVI and CHL incorporates reflectance values in the NIR that are exaggerated if modelled direct irradiance is too small. Wavelength dependent improvements of the applied DOMAC approach appear to mainly affect the visible and less the NIR for inclined surfaces. This might explain the increasing sensitivity of both indices for illumination effects when using DOMAC. Across dense forest, there seems to be no advantage in using irradiance estimates obtained from DART simulations; results are overall very similar to the DEMAC case or slightly worse. The lacking variability in modelled direct irradiance is the primary cause for this. It is likely that the smoothed DEM still provides a better approximation of canopy surfaces than the surface described by the voxel grid. A final issue of note is that we evaluated the improvement of vegetation index retrievals by comparing values of partly shaded canopy areas to those of illuminated canopy areas. This strategy assumes that reflectances and thus indices are identical across illumination conditions if fully corrected. This is an imprecise assumption as the difference is not entirely due to wrong irradiance estimates but also surface properties and plant physiological responses. The PRI, for example, has been shown to vary throughout the day in response to a physiological reaction (de-epoxidation state of xanthophylls) to changing illumination conditions, being enhanced in low-light conditions (Gamon \& Bond, 2013; Hall et al., 2008), while the discussed uncertainty on directional PRI caused by illumination effects is deemed to be of the same magnitude as the physiological response (Mõttus et al., 2015). Separating the three influences on derived vegetation indices represents a challenge and would require extensive field physiological sampling.

\subsection{Towards a reliable retrieval of vegetation information in heterogeneous ca-} nopies

The methods presented here are able to describe the geometrical optical scattering, which dominates at high resolutions, to a certain degree and can partially compensate it, as was demonstrated. However, they cannot sufficiently describe 
volumetric scattering, as occurs within tree canopies. In order to incorporate these kinds of effects, so-called image-based methods are regarded as promising, which are methods that have an increased focus on retrieving unknown parameters in the model based on information contained in the image. There are multiple different implementations of image based methods. Novel approaches seek to describe the radiative transfer in the coupled atmospheric canopy system and move the retrieval problem to the at-sensor radiance level (Laurent et al., 2013). The strength of these TOA approaches is that they avoid error propagation common in other methods due to i) the sequential processing (e.g., posterior anisotropy correction), ii) the retrieval of plant traits via indices and empirical models, and iii) the comparison of different physical quantities (i.e., BRF from canopy radiative transfer models versus HDRF derived from measurements (Laurent et al., 2011). Further methods which are currently being developed are based on empirical cast-shadow detection (Schläpfer et al., 2013) and use a comparison between cast-shadows and illuminated surfaces to derive accurate values for atmospheric visibility. Based on this, the irradiance description for the entire scene can be improved, in turn leading to advanced vegetation information retrieval.

\section{Conclusions}

We provide further experimental evidence that scene reflectance and derived vegetation information is considerably uncertain if the relative contribution of direct and diffuse irradiance to total irradiance is not estimated accurately. We conclude that improvements in the retrieval of surface reflectance and spectral indices by ingesting further auxiliary data to account for varying irradiance fractions in atmospheric correction approaches are limited. Using a DOM or DART simulated irradiance fractions to estimate irradiance leads to some improvements over a simplified approach using spatially coarse resolution DEMs. However, a number of issues and requirements were identified limiting the applicability of the two proposed approaches. This includes the resolution of the 
DOM and the DART voxel grid that should ideally be an order of magnitude larger than the image data. Further, applied approaches are limited in their physical representation of the complex radiative transfer in heterogeneous canopies. DOM based approaches being 2.5 dimensional represents an oversimplification while DART based approaches would require a very large number of scattering angles and iterations to accurately simulate irradiance. As currently the computational requirements for this are still prohibitive, we propose further investigating other options which are promising as operational solutions. Going forward, we emphasize the potential of image-based approaches to derive accurate irradiance fields and vegetation variables. Such approaches include the use of combined atmosphere-surface models with inversion schemes applied on atsensor radiance data or more sophisticated empirical strategies to quantitatively describe the shadow fraction.

\section{Acknowledgements}

The contribution of A. Damm was supported by a grant of the Swiss University Conference and ETH-Board in frame of the KIP-5 project Swiss Earth Observatory Network (SEON) and the contribution of M. E. Schaepman is supported by the University of Zurich Research Priority Program on Global Change and Biodiversity.

\section{References}

Adler-Golden, S. M., Matthew, M. W., Anderson, G. P., Felde, G. W., \& Gardner, J. A. (2002). Algorithm for de-shadowing spectral imagery. In S. S. Shen (Ed.), Imaging Spectrometry. VIII (pp. 203-210). doi:10.1117/12.451691.

Asner, G. P., Martin, R. E., Anderson, C. B., \& Knapp, D. E. (2015). Quantifying forest canopy traits: Imaging spectroscopy versus field survey. Remote Sensing of Environment, 158, 15-27. doi:10.1016/j.rse.2014.11.011. 
Baldocchi, D., Falge, E., Gu, L. H., Olson, R., Hollinger, D., Running, S., Anthoni, P., Bernhofer, C., Davis, K., Evans, R., Fuentes, J., Goldstein, A., Katul, G., Law, B., Lee, X. H., Malhi, Y., Meyers, T., Munger, W., Oechel, W., Paw, K. T., Pilegaard, K., Schmid, H. P., Valentini, R., Verma, S., Vesala, T., Wilson, K., \& Wofsy, S. (2001). FLUXNET: A new tool to study the temporal and spatial variability of ecosystem-scale carbon dioxide, water vapor, and energy flux densities. Bulletin of the American Meteorological Society, 82, 2415-2434. doi:10.1175/1520-0477 (2001) 082<2415: FANTTS>2.3. CO; 2.

Berk, A., Anderson, G. P., Acharya, P. K., Bernstein, L. S., Muratov, L., Lee, J., Fox, M., Adler-Golden, S. M., Chetwynd Jr., J. H., Hoke, M. L., Lockwood, R. B., Gardner, J. A., Cooley, T. W., Borel, C. C., Lewis, P. E., \& Shettle, E. P. (2006). MODTRAN5: 2006 update. In Proceedings of SPIE - The International Society for Optical Engineering.. volume 6233 II. doi:10.1117/ 12.665077 .

Cho, H. K., Jeong, M. J., Kim, J., \& Kim, Y. J. (2003). Dependence of diffuse photosynthetically active solar irradiance on total optical depth. Journal of Geophysical Research: Atmospheres, 108, 4267. doi:10.1029/2002JD002175.

Cogliati, S., Verhoef, W., Kraft, S., Sabater, N., Alonso, L., Vicent, J., Moreno, J., Drusch, M., \& Colombo, R. (2015). Retrieval of sun-induced fluorescence using advanced spectral fitting methods. Remote Sensing of Environment, 169, 344-357. doi:10.1016/j.rse.2015.08.022.

Damm, A., Guanter, L., Laurent, V. C. E., Schaepman, M. E., Schickling, A., \& Rascher, U. (2014). FLD-based retrieval of sun-induced chlorophyll fluorescence from medium spectral resolution airborne spectroscopy data. Remote Sensing of Environment, 147, 256-266. doi:10.1016/j.rse.2014.03.009.

Damm, A., Guanter, L., Paul-Limoges, E., Van der Tol, C., Hueni, A., Buchmann, N., Eugster, W., Ammann, C., \& Schaepman, M. E. (2015a). Farred sun-induced chlorophyll fluorescence shows ecosystem-specific relationships to gross primary production: An assessment based on observational 
and modeling approaches. Remote Sensing of Environment, 166, 91-105. doi:10.1016/j.rse.2015.06.004

Damm, A., Guanter, L., Verhoef, W., Schläpfer, D., Garbari, S., \& Schaepman, M. (2015b). Impact of varying irradiance on vegetation indices and chlorophyll fluorescence derived from spectroscopy data. Remote Sensing of Environment, 156, 202-215. doi:10.1016/j.rse.2014.09.031.

Eugster, W., Zeyer, K., Zeeman, M., Michna, P., Zingg, A., Buchmann, N., \& Emmenegger, L. (2007). Methodical study of nitrous oxide eddy covariance measurements using quantum cascade laser spectrometery over a Swiss forest. Biogeosciences, 4, 927-939. doi:10.5194/bg-4-927-2007.

Friman, O., Tolt, G., \& Ahlberg, J. (2011). Illumination and shadow compensation of hyperspectral images using a digital surface model and non-linear least squares estimation. In Proceedings of SPIE - The International Society for Optical Engineering. volume 8180. doi:10.1117/12.898084.

Gamon, J. A., \& Bond, B. (2013). Effects of irradiance and photosynthetic downregulation on the photochemical reflectance index in Douglas-fir and ponderosa pine. Remote Sensing of Environment, 135, 141-149. doi:10.1016/ j.rse.2013.03.032.

Gamon, J. A., Field, C. B., Bilger, W., Björkman, O., Fredeen, A. L., \& Peñuelas, J. (1990). Remote sensing of the xanthophyll cycle and chlorophyll fluorescence in sunflower leaves and canopies. Oecologia, 85, 1-7. doi:10.1007/BF00317336.

Gamon, J. A., Peñuelas, J., \& Field, C. (1992). A narrow-waveband spectral index that tracks diurnal changes in photosynthetic efficiency. Remote Sensing of Environment, 41, 35-44. doi:10.1016/0034-4257(92)90059-S.

Gamon, J. A., Serrano, L., \& Surfus, J. S. (1997). The photochemical reflectance index: An optical indicator of photosynthetic radiation use efficiency across 
species, functional types, and nutrient levels. Oecologia, 112, 492-501. doi:10. $1007 / \mathrm{s} 004420050337$.

Gastellu-Etchegorry, J.-P., Demarez, V., Pinel, V., \& Zagolski, F. (1996). Modeling radiative transfer in heterogeneous $3-\mathrm{D}$ vegetation canopies. Remote Sensing of Environment, 58, 131-156. doi:10 .1016/0034-4257(95) 00253-7.

Gastellu-Etchegorry, J.-P., Guillevic, P., Zagolski, F., Demarez, V., Trichon, V., Deering, D., \& Leroy, M. (1999). Modeling BRF and radiation regime of boreal and tropical forests. Remote Sensing of Environment, 68, 281-316. doi:10.1016/S0034-4257(98)00119-9.

Gastellu-Etchegorry, J.-P., Yin, T., Lauret, N., Cajgfinger, T., Gregoire, T., Grau, E., Feret, J.-b., Guilleux, J., Cook, B. D., Morton, D., Rubio, J., Durrieu, S., Cazanave, G., Martin, E., Ristorcelli, T., \& Thenkabail, P. S. (2015). Discrete anisotropic radiative transfer (DART 5) for modelling airborne and satellite spectroradiometer and LIDAR acquisitions of natural and urban landscapes. Remote Sensing, 7, 1667-1701. doi:doi:10.3390/rs70201667.

Gitelson, A. A., Keydan, G. P., \& Merzlyak, M. N. (2006). Three-band model for noninvasive estimation of chlorophyll, carotenoids, and anthocyanin contents in higher plant leaves. Geophysical Research Letters, 33, L11402. doi:10. 1029/2006GL026457.

Hall, F. G., Hilker, T., Coops, N. C., Lyapustin, A., Huemmrich, K. F., Middleton, E., Margolis, H., Drolet, G., \& Black, T. A. (2008). Multi-angle remote sensing of forest light use efficiency by observing PRI variation with canopy shadow fraction. Remote Sensing of Environment, 112, 3201-3211. doi:10.1016/j.rse.2008.03.015.

Holben, B. N., Eck, T. F., Slutsker, I., Tanré, D., Buis, J. P., Setzer, A., Vermote, E., Reagan, J. A., Kaufman, Y. J., Nakajima, T., Lavenu, F., Jankowiak, I., \& Smirnov, A. (1998). AERONET - A Federated Instrument Network and Data Archive for Aerosol Characterization. Remote Sensing of Environment, 66 , 1-16. doi:10.1016/S0034-4257(98)00031-5. 
Hueni, A., Biesemans, J., Meuleman, K., Dell'Endice, F., Schläpfer, D., Odermatt, D., Kneubühler, M., Adriaensen, S., Kempenaers, S., Nieke, J., \& Itten, K. I. (2009). Structure, components, and interfaces of the airborne prism experiment (APEX) processing and archiving facility. IEEE Transactions on Geoscience and Remote Sensing, 47, 29-43. doi:10.1109/TGRS.2008.2005828.

Itten, K. I., \& Meyer, P. (1993). Geometric and radiometric correction of TM data of mountainous forested areas. IEEE Transactions on Geoscience and Remote Sensing, 31, 764-770. doi:10.1109/36.239898.

Key, J. R., \& Schweiger, A. J. (1998). Tools for atmospheric radiative transfer: STREAMER and FLUXNET. Computers and Geosciences, 24, 443-451. doi:10.1016/S0098-3004(97)00130-1.

Kokaly, R. F., Asner, G. P., Ollinger, S. V., Martin, M. E., \& Wessman, C. A. (2009). Characterizing canopy biochemistry from imaging spectroscopy and its application to ecosystem studies. Remote Sensing of Environment, 113, S78-S91. doi:10.1016/j.rse.2008.10.018.

Kükenbrink, D., Leiterer, R., Schneider, F. D., Schaepman, M. E., \& Morsdorf, F. (2016). Quantification of hidden canopy volume of airborne laser scanning data using a voxel traversal algorithm. Remote Sensing of Environment, In Press. doi:10.1016/j.rse.2016.10.023.

Laurent, V. C., Verhoef, W., Clevers, J. G., \& Schaepman, M. E. (2011). Estimating forest variables from top-of-atmosphere radiance satellite measurements using coupled radiative transfer models. Remote Sensing of Environment, 115, 1043-1052. doi:10.1016/j.rse.2010.12.009.

Laurent, V. C., Verhoef, W., Damm, A., Schaepman, M. E., \& Clevers, J. G. P. W. (2013). A Bayesian object-based approach for estimating vegetation biophysical and biochemical variables from APEX at-sensor radiance data. Remote Sensing of Environment, 139, 6-17. doi:10.1016/j.rse.2013.07. 032. 
Malenovský, Z., Bartholomeus, H. M., Acerbi-Junior, F. W., Schopfer, J. T., Painter, T. H., Epema, G. F., \& Bregt, A. K. (2007). Scaling dimensions in spectroscopy of soil and vegetation. International Journal of Applied Earth Observation and Geoinformation, 9, 137-164. doi:10.1016/j.jag.2006.08. 003.

Malenovský, Z., Homolová, L., Zurita-Milla, R., Lukeš, P., Kaplan, V., Hanuš, J., Gastellu-Etchegorry, J. P., \& Schaepman, M. E. (2013). Retrieval of spruce leaf chlorophyll content from airborne image data using continuum removal and radiative transfer. Remote Sensing of Environment, 131, 85-102. doi:10. 1016/j.rse.2012.12.015.

Matthew, M. W., Adler-Golden, S. M., Berk, A., Felde, G., Anderson, G. P., Gorodetzky, D., Paswaters, S., \& Shippert, M. (2002). Atmospheric correction of spectral imagery: Evaluation of the FLAASH algorithm with AVIRIS data. In Proceedings of the 31st Applied Imagery Pattern Recognition Workshop (pp. 157-163). Washington, DC. doi:10.1109/AIPR.2002.1182270.

Mõttus, M., Takala, T. L., Stenberg, P., Knyazikhin, Y., Yang, B., \& Nilson, T. (2015). Diffuse sky radiation influences the relationship between canopy PRI and shadow fraction. ISPRS Journal of Photogrammetry and Remote Sensing, 105, 54-60. doi:10.1016/j.isprsjprs.2015.03.012.

Ouaidrari, H., \& Vermote, E. F. (1999). Operational atmospheric correction of Landsat TM data. Remote Sensing of Environment, 70, 4-15. doi:10.1016/ S0034-4257 (99) 00054-1.

Rascher, U., Alonso, L., Burkart, A., Cilia, C., Cogliati, S., Colombo, R., Damm, A., Drusch, M., Guanter, L., Hanus, J., Hyvärinen, T., Julitta, T., Jussila, J., Kataja, K., Kokkalis, P., Kraft, S., Kraska, T., Matveeva, M., Moreno, J., Muller, O., Panigada, C., Pikl, M., Pinto, F., Prey, L., Pude, R., Rossini, M., Schickling, A., Schurr, U., Schüttemeyer, D., Verrelst, J., \& Zemek, F. (2015). Sun-induced fluorescence - a new probe of photosynthesis: First maps from 
the imaging spectrometer HyPlant. Global Change Biology, 21, 4673-4684. doi:10.1111/gcb.13017.

Richter, R. (1990). A fast atmospheric correction algorithm applied to Landsat TM images. International Journal of Remote Sensing, 11, 159-166. doi:10. $1080 / 01431169008955008$.

Richter, R. (1998). Correction of satellite imagery over mountainous terrain. Applied Optics, 37, 4004-4015. doi:10.1364/A0.37.004004.

Richter, R., \& Schläpfer, D. (2002). Geo-atmospheric processing of airborne imaging spectrometry data. Part 2: Atmospheric/ topographic correction. International Journal of Remote Sensing, 23, 2631-2649. doi:10 . $1080 / 01431160110115834$.

Richter, R., \& Schläpfer, D. (2016). Atmospheric / Topographic Correction for Airborne Imagery (ATCOR-4 User Guide). (7th ed.). DLR, Wessling, Germany.

Richter, R., Schläpfer, D., \& Müller, A. (2011). Operational atmospheric correction for imaging spectrometers accounting for the smile effect. IEEE Transactions on Geoscience and Remote Sensing, 49, 1772-1780. doi:10.1109/ TGRS . 2010 . 2089799.

Sandmeier, S., \& Itten, K. I. (1997). A physically-based model to correct atmospheric and illumination effects in optical satellite data of rugged terrain. IEEE Transactions on Geoscience and Remote Sensing, 35, 708-717. doi:10.1109/36.581991.

Schaepman, M. E., Jehle, M., Hueni, A., D’Odorico, P., Damm, A., Weyermann, J., Schneider, F. D., Laurent, V., Popp, C., Seidel, F. C., Lenhard, K., Gege, P., Küchler, C., Brazile, J., Kohler, P., De Vos, L., Meuleman, K., Meynart, R., Schläpfer, D., Kneubühler, M., \& Itten, K. I. (2015). Advanced radiometry measurements and Earth science applications with the Airborne 
Prism Experiment (APEX). Remote Sensing of Environment, 158, 207-219. doi:10.1016/j.rse.2014.11.014.

Schaepman, M. E., Ustin, S. L., Plaza, A. J., Painter, T. H., Verrelst, J., \& Liang, S. (2009). Earth system science related imaging spectroscopy-An assessment. Remote Sensing of Environment, 113, S123-S137. doi:10.1016/j . rse.2009.03.001.

Schaepman-Strub, G., Schaepman, M. E., Painter, T. H., Dangel, S., \& Martonchik, J. V. (2006). Reflectance quantities in optical remote sensingdefinitions and case studies. Remote Sensing of Environment, 103, 27-42. doi:10.1016/j.rse.2006.03.002.

Schläpfer, D., Koetz, B., Gruber, S., \& Morsdorf, F. (2003). The influence of DEM characteristics on preprocessing of DAIS / ROSIS data in high altitude alpine terrain. In 3rd EARSeL Workshop on Imaging Spectroscopy (pp. 1316). Herrsching, Germany.

Schläpfer, D., \& Richter, R. (2002). Geo-atmospheric processing of airborne imaging spectrometry data. Part 1: Parametric orthorectification. International Journal of Remote Sensing, 23, 2609-2630. doi:10.1080/ 01431160110115825.

Schläpfer, D., Richter, R., \& Damm, A. (2013). Correction of shadowing in imaging spectroscopy data by quantification of the proportion of diffuse illumination. In 8th EARSeL Workshop on Imaging Spectroscopy. Nantes, France.

Schneider, F. D., Leiterer, R., Morsdorf, F., Gastellu-Etchegorry, J. P., Lauret, N., Pfeifer, N., \& Schaepman, M. E. (2014). Simulating imaging spectrometer data: 3D forest modeling based on LiDAR and in situ data. Remote Sensing of Environment, 152, 235-250. doi:10.1016/j.rse.2014.06.015.

Schneider, F. D., Leiterer, R., Schaepman, M. E., \& Morsdorf, F. (2015). Canopy height and plant area index changes in a temperate forest bet- 
ween 2010 - 2014 using airborne laser scanning. In S. Durrieu, \& C. Véga (Eds.), Proceedings of SilviLaser 2015, 14th conference on Lidar Applications for Assessing and Managing Forest Ecosystems. La Grande Motte, France. doi:10.5167/uzh-116915.

Seidel, F. C., Kokhanovsky, A. A., \& Schaepman, M. E. (2010). Fast and simple model for atmospheric radiative transfer. Atmospheric Measurement Techniques, 3, 1129-1141. doi:10.5194/amt-3-1129-2010.

Seidel, F. C., Kokhanovsky, A. A., \& Schaepman, M. E. (2012). Fast retrieval of aerosol optical depth and its sensitivity to surface albedo using remote sensing data. Atmospheric Research, 116, 22-32. doi:10.1016/j.atmosres . 2011.03 .006$.

Teillet, P. M., Guindon, B., \& Goodenough, D. G. (1982). On the slope-aspect correction of multispectral scanner data. Canadian Journal of Remote Sensing, 8, 84-106. doi:10.1080/07038992.1982.10855028.

Tucker, C. J. (1979). Red and photographic infrared linear combinations for monitoring vegetation. Remote Sensing of Environment, 8, 127-150. doi:10. 1016/0034-4257 (79) 90013-0.

Ustin, S. L., Gitelson, A. A., Jacquemoud, S., Schaepman, M. E., Asner, G. P., Gamon, J. A., \& Zarco-Tejada, P. (2009). Retrieval of foliar information about plant pigment systems from high resolution spectroscopy. Remote Sensing of Environment, 113, S67-S77. doi:10.1016/j.rse.2008.10.019.

Van der Tol, C., Verhoef, W., Timmermans, J., Verhoef, A., \& Su, Z. (2009). An integrated model of soil-canopy spectral radiances, photosynthesis, fluorescence, temperature and energy balance. Biogeosciences, 6, 3109-3129. doi:10.5194/bg-6-3109-2009.

Verhoef, W., \& Bach, H. (2003). Simulation of hyperspectral and directional radiance images using coupled biophysical and atmospheric radiative 
transfer models. Remote Sensing of Environment, 87, 23-41. doi:10.1016/ S0034-4257(03) 00143-3.

Verhoef, W., \& Bach, H. (2012). Simulation of Sentinel-3 images by four-stream surface-atmosphere radiative transfer modeling in the optical and thermal domains. Remote Sensing of Environment, 120, 197-207. doi:10.1016/j. rse.2011.10.034

Verhoef, W., Van der Tol, C., \& Middleton, E. M. (2014). Vegetation canopy fluorescence and reflectance retrieval by model inversion using optimization. In 5th International Workshop on Remote Sensing of Vegetation Fluorescence (pp. 759-770). Paris, France.

Wulder, M. A., Hall, R. J., Coops, N. C., \& Franklin, S. E. (2004). High Spatial Resolution Remotely Sensed Data for Ecosystem Characterization. BioScience, 54, 511-521. doi:10.1641/0006-3568 (2004) 054 [0511 :HSRRSD] $2.0 . \mathrm{CO} ; 2$.

Yin, T., Gastellu-Etchegorry, J. P., Lauret, N., Grau, E., \& Rubio, J. (2013). A new approach of direction discretization and oversampling for 3D anisotropic radiative transfer modeling. Remote Sensing of Environment, 135, 213-223. doi:10.1016/j.rse.2013.03.030.

\section{List of Figures}

1 APEX flight line (at-sensor radiance, RGB colour composite) of the Laegern study site (June 26, 2010, 15:30 UTC). The background is a hillshaded DEM illustrating scene topography (DHM25 from Swisstopo, Switzerland). . . . . . . . . . . . 5 